\title{
Keteramatan Sistem Deskriptor Kontinu
}

\author{
Muhammad Wakhid Musthofa ${ }^{1}$ dan Ari Suparwanto ${ }^{2}$ \\ 'Program Studi Pendidikan Matematika, Fakultas Sains dan Teknologi, UIN Sunan Kalijaga, \\ Jl. Marsda Adisucipto No. 1 Yogyakarta 55281, Indonesia \\ 2Program Program Studi Matematika Universitas Gadjah Mada Yogyakarta, Bulaksumur Yogyakarta \\ 55281, Indonesia
}

Korespondensi; Muhammad Wakhid Musthofa, Email: mwakhid_m@yahoo.com

\begin{abstract}
Abstrak
Dalam makalah ini dapat diamati sistem deskriptor kontinyu dari bentuk $E(t)=A(t)+B(t), x(0)=x_{0}$ akan dipelajari, dimana $E, A$ dan $B$ adalah matriks konstan yang mungkin tunggal Dan $u(t)$ adalah fungsi kontinyu piecewise yang dibedakan $(m-1)$ kali, di mana $m$ adalah tingkat sistem nilpotency. Dua definisi tentang pengamatan sistem deskriptor beserta karakterisasi mereka yang diberikan oleh Dai dan Yip akan dibahas, kemudian hubungan dan perbandingan antara karakterisasi ini akan dipresentasikan.
\end{abstract}

Kata Kunci: O bservability; Sistem deskriptor kontinu

\begin{abstract}
In this paper the observability of continuous descriptor system of the form $E(t)=A(t)+B(t), x(0)=x_{0}$ will be studied, where $E, A$ and $B$ are constant matrices that may be singular and $u(t)$ is piecewise continuous function which is differentiated $(m-1)$ times, where $m$ is the degree of nilpotency system. Two definitions about observability of descriptor systems along with their characterizations given by Dai and Yip will be both discussed, then further the relationship and comparison between these characterizations will be presented.
\end{abstract}

Keywords: O bservability; Continuous descriptor system

\section{Pendahuluan}

Bentuk model representasi state space telah banyak digunakan untuk menyajikan masalah dalam dunia sains dan teknik. Pemodelan dalam bentuk ini memudahkan bagi seorang analis untuk mendesain kendali yang akan embuat perilaku dari sistem sesuai dengan yang diharapkan. Namun, pada kenyatannya tidak semua sistem dapat dimodelkan dalam bentuk state space.Dalam hal ini, sistem deskriptor mampu mengatasi permasalahan tersebut disebabkan bentuknya yang lebih umum dan kemampuannya untuk mempertahankan struktur fisik dari sistem dan mampu memperhatikan mode nondinamik dan mode impulsif. Beberapa sistem yang hanya dapat direpresentasikan dalam bentuk sistem deskriptor diantaranya adalah sistem jaringan listrik, sistem yang terperturbasi secara singular, sistem komposit, dan model Leontif pada multisektor ekonomi.

Salah satu konsep penting dalam pembahasan sistem deskriptor adalah mengenai keteramatan sistem. Melalui konsep keteramatan, keadaan awal dari suatu sistem dapat diketahui hanya dengan bermodalkan informasi terkini dari sistem. Dalam makalah ini keteramatan sistem deskriptor akan dibahas berdasarkan konsep dan karakterisasi yang disajikan oleh Dai dan Yip [3], [5].

Metode yang digunakan dalam makalah ini adalah studi komparasi. Dua kreteria keteramatan yang disajikan oleh Dai dan Yip akan dikaji dan dikomparasikan persamaan berikut perbedaannya. Selanjutnya akan dicari hubungan dari dua karakterisasi tersebut beserta titik temunya. 


\section{Keberadaan Solusi Dan Ketercapaian Sistem Deskriptor Kontinu}

Sistem yang akanmenjadi fokus pembahasan dalam makalah ini adalah sistem dengan bentuk representasi

$$
E(t)=A(t)+B(t), x(0)=x_{0}
$$

dengan $E, A$ adalah matriks konstan berukuran $n, B$ adalah matriks konstan berukuran $n$, dan $u(t)$ adalah fungsi yang kontinu sepotong-sepotong dan terdiferensial pada tingkat yang cukup. Keberadaan solusi dari sistem (1) dikarakterisasi oleh regularitas sistem (1) yang didefinisikan sebagai berikut.

Definisi 2.1. [2] Untuk suatu matriks $E, A$ sembarang, pensil $(E, A)$ dikatakan regular jika terdapat scalar yang konstan $\lambda \in C$ sedemikian sehingga $|\lambda+A| \neq 0$ atau ekuivalen dengan $|A-\lambda| \neq 0$.

Definisi 2.2. [5] Sistem deskriptor ( $I$ ) mempunyai solusi jika matriks pensil $(E, A)$ regular, yaitu $|\lambda+A| \neq 0$

Selanjutnya, diberikan lemma yang sangat bermanfaat untuk menentukan regularitas suatu sistem deskriptor.

Lemma 2.3. [2], [3], [4] pensil $(E, A)$ regular jika dan hanya jika dapat dipilih suatu matriks nonsingular $P$ dan $Q$ sedemikian sehingga

$$
Q=d \quad\left(l_{n 1}, N\right), Q=d \quad\left(A_{1}, l_{n 2}\right)
$$

Dengan $n_{1}+n_{2}=n, A_{1} \in R^{n_{1} x n_{1}}$ dan $N \in R^{n_{2} x n_{2}}$ adalah matriks nilpotent.

Lemma di atas menunjukkan bahwa untuk suatu sistem deskriptor (1), terdapat matriks nonsingular $P$ dan $Q$ sedemikian sehingga sistem (1) ekuivalen terhadap sistem

$$
\begin{aligned}
& \dot{x}_{1}(t)=A_{1} x_{1}(t)+B_{1} u(t) \\
& N \dot{x}_{2}(t)=x_{2}(t)+B_{2} u(t)
\end{aligned}
$$

Dengan transformasi koordinat diberikan oleh

$$
\left[\begin{array}{l}
x_{1} \\
x_{2}
\end{array}\right]=P^{-1} x, x_{1} \in R^{n_{1}}, x_{2} \in R^{n_{2}}
$$

Dan

Dengan:

$$
Q=d \quad\left(l_{n 1}, N\right), Q=d \quad\left(A_{1}, l_{n 2}\right), Q=\left[\begin{array}{l}
B_{1} \\
B_{2}
\end{array}\right]
$$

$A_{1} \quad$ : matriks berukuran $n_{1} x n_{1}$

$N \quad$ : matriks berukuran $n_{2} x n_{2}$ dengan sifat $N^{m}=0, N^{m-1} \neq 0$

$B_{1} \quad$ : matriks berukuran $n_{1} x$

$B_{2} \quad$ : matriks berukuran $n_{2} x$

$x_{1}(t)$ : vektor variable state di $C^{n_{1}}$

$x_{2}(t)$ : vektor variabel state di $C^{n_{2}}$

$u(t)$ : fungsi yang terdiferensial sampai minimal $m-1$ kali. 
Sistem (3) disebut bentuk kanonik standar dari sistem deskriptor (1) dan $\mathrm{m}$ disebut sebagai derajat kenilpotenan sistem (3).Subsistem (3.a) sering diistilahkan dengan sebutan subsistem lambat sedangkan subsistem (3.b) diistilahkan dengan subsistem cepat.Solusi eksak dari sistem (3) diatas diberikan oleh

$$
\begin{aligned}
x(t) & =P\left[\begin{array}{l}
I \\
0
\end{array}\right] x_{1}(t)+P\left[\begin{array}{l}
0 \\
l
\end{array}\right] x_{2}(t) \\
& =P\left[\begin{array}{l}
I \\
0
\end{array}\right]\left(e^{A_{1} t} x_{1}(0)+\int_{0}^{t} e^{A_{1}(t-\tau)} B_{1} u(\tau) d\right)-P\left[\begin{array}{l}
0 \\
l
\end{array}\right] \sum_{i=0}^{m-1} N^{i} B_{2} u^{(i)}(t)
\end{aligned}
$$

Dalam pembahasan selanjutnya diasumsikan bahwa sistem deskriptor (1) mempunyai solusi dan sistem tersebut ekuivalen dengan sistem (3).Berikut diberikan lemma yang memberikan batasan syarat awal yang diperkenankan bagi sistem deskriptor (3).

Lemma 2.4. Diberikan $u$ adalah himpunan fungsi-fungsi $u(t) \in C^{k}$ sedemikian sehingga $u(t)$ terdiferensial minimal sebanyak $m-1$ kali. Himpunan syarat awal yang diperkenankan untuk sistem (3) diberikan oleh

$$
l=\left\{\left[\begin{array}{l}
x_{1} \\
x_{2}
\end{array}\right] \mid x_{1} \in C^{n_{1}}, x_{2} \in \sum_{i=0}^{m-1} N^{i} B_{2} u^{(i)}(0), u \in u\right\}
$$

Jelas bahwa vektor 0 berada dalam himpunan $I$, sebab terdapat $u \in u$ sedemikian sehingga $u^{(i)}(0)=$ 0 untuk $i=1,2, \ldots$.

Sebelum lebih jauh membahas syarat awal yang diperkenankan untuk suatu sistem deskriptor, berikut diberikan definisi notasi $\langle\bullet \mid \bullet\rangle$ yang akan digunakan pada pembahasan selanjutnya.

Definisi 2.5. Untuk sembarang matriks $A$ berukuran $n$ dan $B$ matriks dengan ukuran yang sesuai dengan haisl kali $A$ terdefinisi, notasi $\langle$.$| . \rangle$ didefinisikan sebagai

$$
\langle A \mid B\rangle=l l\left[\begin{array}{llll}
A & B & \cdots & A^{n-1} B
\end{array}\right]
$$

Pembahasan tentang keteramatan sistem deskriptor tidak bisa dilepaskan dengan konsep ketercapaian (reachability) sistem desktiptor.Berikut diberikan definisi ketercapaian sistem desktiptor.

Definisi 2.6. [5] Diberikan sistep deskriptor (3). State $x_{1}$ dikatakan dapat diraih dari state $x_{0}$ jika terdapat $u \in u$ sedemikian sehingga solusi dari sistem (3) yaitu $x(t)=\left[\begin{array}{l}x_{1}(t) \\ x_{2}(t)\end{array}\right]$ mempunyai $x(0)=x_{0}$ dan $x\left(t_{1}\right)=x_{1}$ untuk $t_{1}>0$.

Notasi $R(x)$ menyatakan himpunan state-state yang tercapai dari state $x \in 1$. Dai [2] mengkarakterisasi himpunan state-state yang tercapai dari state $x_{0}=0$ dalam teorema berikut.

Teorema 2.7. Jika $R(0)$ menyatakan himpunan state-state yang tercapai dari state $x_{0}=0$ maka

$$
R(0)=\left\langle A_{1} \mid B_{1}\right\rangle \oplus\left\langle N \mid B_{2}\right\rangle
$$

Teorema di atas dapat digeneralisasi untuk suatu nilai awal $x_{0}$ dengan kondisi tertentu yang diberikan oleh teorema berikut. 
Teorema 2.8. Misalkan $I_{0}$ adalah himpunan syarat awal yang diperkenankan untuk sistem (3) sedemikian sehingga komponen yang bersesuaian dengan subsistem lambat bernilai nol, yaitu

$$
I_{0}=\left\{\left[\begin{array}{l}
x_{1} \\
x_{2}
\end{array}\right] \mid x_{1}=0, x_{2}=-\sum_{i=0}^{m-1} N^{i} B_{2} u^{(i)}, u \in u\right\}
$$

Maka, untuk setiap $x_{0} \in I_{0}, R\left(x_{0}\right)=\left\langle A_{1} \mid B_{1}\right\rangle \oplus\left\langle N \mid B_{2}\right\rangle$.

Himpunan lengkap untuk syarat awal yang diperkenankan untuk sistem (3) adalah

$$
l=C^{n_{1}} \oplus\left\langle N \mid B_{2}\right\rangle
$$

Jika $\hat{x} \in I$ maka

$$
R(\hat{x})=\left\langle A_{1} \mid B_{1}\right\rangle \oplus\left\langle N \mid B_{2}\right\rangle+H(x)
$$

Dengan $H(x)=\left\{\left[\begin{array}{l}z_{1} \\ z_{2}\end{array}\right] \mid z_{1}=e^{t E_{1}} x_{1}, t>0, z_{2}=0\right\}$

Dengan demikian maka himpunan lengkap state-state teraih diberikan oleh

$$
R=\bigcup_{x \in I} R(x)=C^{n_{1}} \oplus\left\langle N \mid B_{2}\right\rangle
$$

Sehingga $l=R$.

\section{Keteramatan Sistem Deskriptor Kontinu}

Dalam makalah ini akan dibahas keteramatan sistem deskriptor kontinu dengan persamaan state space dan output yang disajikan dengan persamaan

$$
\dot{x}_{1}(t)=A(t)+B(t), x(0)=x_{0}
$$

Dengan $E, A, B, x(t), u(t)$ sebagaimana didefinisikan dalam sistem (1) dan $C$ adalah matriks konstan berukuran $n$ dan $y(t)$ adalah vektor dari $C^{r}$. Dikarenakan sistem deskriptor (13) regular maka sistem tersebut ekuivalen dengan sistem deskriptor.

$$
\begin{aligned}
& \dot{x}_{1}(t)=A_{1} x_{1}(t)+B_{1} u(t) \\
& N \dot{x}_{2}(t)=x_{2}(t)+B_{2} u(t) \\
& y(t)=C_{1} x_{1}(t)+C_{2} x_{2}(t)
\end{aligned}
$$

Keteramatan sistem (13) dan (14) diberikan oleh Dai dalam definisi berikut.

Definisi 3.1 [2] sistem (13) dan (14) dikatakan teramati jika kondisi awal $x(0)$ dapat ditentukan dengan tunggal oleh $u(t)$ dan $y(t)$ dengan $0 \leq t<\infty$.

Berdasarkan definisi 3.1 Dai mengkarakterisasi keteramatan sistem deskriptor (13) dan (14) dalam teorema di bawah ini. 
Teorema 3.2. [2] Pernyataan-pernyataan berikut ekuivalen.

a. Sistem deskriptor (13) teramati.

b. Subsistem lambat (14.a) dan subsstem cepat (14.b) teramati.

c. $\operatorname{Rank}\left[\begin{array}{cc}S & -A \\ C^{T}\end{array}\right]=n$, untuk semua scalar $s \in C, s$ berhingga dan rank $\left[\begin{array}{l}E \\ C\end{array}\right]=n$.

Karakterisasi di atas sering dipakai dan dirujuk oleh banyak penulis dan peneliti.Definisi yang sama diberikan oleh Cristodoulou [1]. Berbeda dengan Dai, Yip dan Sincovec mempunyai definisi lain bagi sistem deskriptor (13) dan (14).

Definisi 3.3. [5] Sistem (13) dikatakan teramati jika untuk $t \geq 0, x(t)$ dapat ditentukan dari $E, A, B, y(\tilde{t})$ dan $u(\tilde{t})$ untuk suatu $\tilde{t} \in[0, b]$.

Definisi di atas menyatakan sesuatu yang berbeda dengan definisi 5 yang ditulis oleh Dai. Berikut akan diberikan ulasan ekuivalensi dua definisi tersebut.

Misalkan kondisi awal $x(0)$ dapat ditentukan dengan tunggal oleh $u(t)$ dan $y(t)$ dengan $0 \leq t<$ $\infty$ dan akan dibuktikan $x(t)$ dapat ditentukan dari $E, A, B, y(\tilde{t})$ dan $u(\tilde{t})$ untuk suatu $\tilde{t} \in[0, b]$. Karena untuk setiap nilai awal $x(0)$ akan mengkonstruksikan dengan tunggal trayektori $x(t)$ maka jika $x(0)$ telah dapat ditentukan dengan tunggal oleh $u(t)$ dan $y(t)$ dengan $0 \leq t<\infty$, jelah hal ini akan berakibat $x(t)$ akan dapat ditentukan dengan tunggal pula dari $x(0)$. Selanjutnya berdasarkan definisi $x(t)$ pada persamaan (5) maka $x(t)$ akan tertentu dengan tunggal dari $E, A, B, y(\tilde{t})$ dan $u(\tilde{t})$ untuk suatu $\tilde{t} \in[0, b]$.

Dilain pihak, jika diketahui $x(t)$ dapat ditentukan dari $E, A, B, y(\tilde{t})$ dan $u(\tilde{t})$ untuk suatu $\tilde{t} \in[0, b]$ maka berdasarkan persamaan (5), $x(0)$ dapat ditentukan dengan tunggal oleh $u(t)$ dan $y(t)$ dengan $0 \leq t<\infty$. Dengan demikian telah terbukti ekuivalensi dari definisi 5 dan definisi 6 .

Selanjutnya Yip dan Sincovec menyederhanakan definisi 6 di atasberdasarkan fakta bahwa variabel $x_{2}(t)$ dalam sistem deskriptor (14.b) selalu dapat ditentukan dari persamaan

$$
x_{2}(t)=-\sum_{i=0}^{m-1} N^{i} B_{2} u^{(i)}(t)
$$

Untuk suatu $N, B_{2}$, dan $u(t)$ yang diberikan. Hal ini dikarenakan berdasarkan Lemma 2, syarat awal $x_{2}(0)$ hanya bisa diambil dari himpunan $l$ dalam persamaan (6), sehingga $x_{2}(t)$ pasti dapat ditentukan dari persamaan (15). Berdasarkan fakta tersebut didapat definisi berikut.

Definisi 3.4 [5] Sistem (14) dikatakan teramati jika untuk $t \geq 0, x_{1}(t)$ dapat ditentukan dari $A_{1}, B_{1}, C_{1}, y(t)-C_{2} x_{2}(t)$, dan $u(t)$.

Dengan demikian Yip dan Sincovec mengkarakterisasi keteramatan sistem deskriptor (14) hanya melalui subsistem lambatnya berdasarkan fakta bahwa semua state $x_{2}(t)$ selalu dapat ditentukan dari persamaan (15) yang berarti subsistem cepat dari sistem (14) selalu teramati. Berdasarkan hal tersebut, Yip dan Sincovecmenyajikan teorema berikut.

Teorema3.5. [5] Sistem (14) dikatakan teamati jika dan hanya jika subsistem lambatnya teramati.

Berdasarkan teorema 3.4 didapatkan akibat berikut.

Akibat 3.6. [5] Sistem (14) teramati jika dan hanya jika matriks augmented berikut

$$
T=\left[\begin{array}{llll}
C_{1}^{T} & A_{1}^{T} C_{1}^{T} & \cdots & \left(A_{1}^{T}\right)^{n_{1}-1} C_{1}^{T}
\end{array}\right]
$$

Mempunyai rank $n_{1}$. 
Teorema berikut merupakan konsekuensi dari teorema 3.4.

Teorema 3.7. [5] Sistem deskriptor (13) dikatakan teramati jika dan hanya jika matriks augmented $\left[\begin{array}{lll}(s-A)^{T} & C^{T}\end{array}\right]$ mempunyai rank penuh.

Tampak bahwa karakterisasi keteramatan sistem deskriptor kontinu (13) dan (14) yang diberikan oleh Yip dalam Teorema 5 berbeda dengan karakterisasi yang diberikan oleh Dai dalam teorema 3. Ketiadaan syarat rank $\left[\begin{array}{l}E \\ C\end{array}\right]=n$ pada kriteria keteramatan sistem deskriptor dalam Teorema 5 dikarenakan Yip hanya mengkarakterisasi keteramatan sistem deskriptor berdasarkan keteramatan subsistem lambatnya dengan memastikan bahwa subsistem cepatnya teramati berdasarkan batasan yang diberikan oleh Lemma 2. Lemma tersebut membatasi bahwa syarat awal dari sistem hanya bisa diambil dari himpunan $I$ dalam persamaan (6). Sedangkan Dai, di lain pihak tidak memberikan batasan syarat awal pada sistem. Semua state $x=P\left[\begin{array}{l}x_{1} \\ x_{2}\end{array}\right] \in R^{n_{1}+n_{2}}$ dapat menjadi syarat awal bagi sistem. Sehingga keteramatan sistem masih perlu ditinjau dari sisi subsistem cepat maupun subsistem lambatnya. Dengan demikian dapat dikatakan bahwa definisi dan karakterisasi keteramatan sistem deskriptor yang diberikan oleh Yip adalah kejadian khusus dari definisi dan karakterisasi keteramatan sistem deskriptor yang diberikan oleh Dai.

Contoh berikut mengilustrasikan penerapan karakterisasi keteramatan sistem dari dai dan Yip. Contoh 3.8. Diberikan sistem sirkuit listrik yang disajikan dalam gambar berikut.

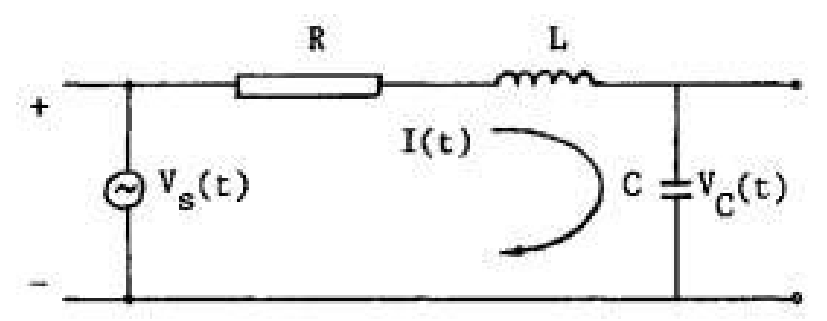

Gambar 1 Sirkuit listrik.

Dengan memilih variabel state $x(t)=\left[\begin{array}{llllll}I(t) & V_{L}(t) & V_{C}(t) & V_{R}(t)\end{array}\right]^{T}$ kendali input $V_{S}(t)$, output terukur $V_{C}(t)$, dan nilai $L=C=R=1$ didapat persamaan state berikut

$$
\left[\begin{array}{cccc}
1 & 0 & 0 & 0 \\
0 & 0 & 1 & 0 \\
0 & 0 & 0 & 0 \\
0 & 0 & 0 & 0
\end{array}\right] \dot{x}(t)=\left[\begin{array}{cccc}
0 & 1 & 0 & 0 \\
1 & 0 & 0 & 0 \\
-1 & 0 & 0 & 1 \\
0 & 1 & 1 & 1
\end{array}\right] x(t)+\left[\begin{array}{c}
0 \\
0 \\
0 \\
-1
\end{array}\right] V_{S}(t)
$$

$y(t)=\left[\begin{array}{llll}0 & 0 & 1 & 0\end{array}\right] x(t)$.

Dekomposisi standart dari sistem (16) di atas adalah

$$
\dot{x}_{1}(t)=\left[\begin{array}{cc}
-1 & -1 \\
1 & 0
\end{array}\right] x_{1}(t)+\left[\begin{array}{l}
1 \\
0
\end{array}\right] V_{S}(t)
$$

$0=x_{2}(t)+\left[\begin{array}{c}-1 \\ 0\end{array}\right] V_{S}(t)$ 
Berdasarkan persamaan (5) solusi dari sistem (17) diberikan oleh

$$
\begin{gathered}
x_{1}(t)=e^{A_{1} t} x_{1}(0)+\int_{0}^{t} e^{A_{1}(t-\tau)}\left[\begin{array}{l}
1 \\
0
\end{array}\right] V_{S}(\tau) d \\
x_{2}(t)=\left[\begin{array}{l}
1 \\
0
\end{array}\right] V_{S}(t)
\end{gathered}
$$

Dengan perhitungan sederhana diperoleh

$$
\operatorname{rank}[s E-A]=\left[\begin{array}{cccc}
s & -1 & 0 & 0 \\
-1 & 0 & 1 & 0 \\
1 & 0 & 0 & -1 \\
0 & -1 & -1 & -1 \\
0 & 0 & 1 & 0
\end{array}\right]=4 \text { dan } \operatorname{rank}\left[\begin{array}{c}
E \\
C
\end{array}\right]=\left[\begin{array}{cccc}
1 & 0 & 0 & 0 \\
0 & 0 & 1 & 0 \\
0 & 0 & 0 & 0 \\
0 & 0 & 0 & 0 \\
0 & 0 & 1 & 0
\end{array}\right]=2 \text {. }
$$

Hal tersebut menunjukkan subsistem lambat dari sistem (17) teramati tetapi subsistem cepatnya tidak teramati. Sehingga berdasarkan kriteria keteramatan Dai (Teorema 3) sistem (16) atau (17) tidak teramati. Di lain pihak, menurut kriteria keteramatan Yip (Teorema 5) sistem (16) atau (17) teramati. Ketidakteramatan sistem (16) atau (17) menurut kriteria Dai dikarenakan tidak semua syarat awal $x_{2}(0)$ berada dalam himpunan syarat awal yang diperkenankan.

$$
\left\{\left\{x_{2}(0) \in R^{2}\right\} \mid x_{2}(0)=\left[\begin{array}{l}
1 \\
0
\end{array}\right] V_{S}(0)\right\}
$$

Tetapi berdasarkan kriteria keteramatan Yip sistem (16) atau (17) teramati selama syarat awal $x_{2}(0)$ diambil dari himpunan (19).

\section{Kesimpulan}

Berdasarkan kajian pada definisi dan karakterisasi keteramatan sistem deskriptor kontinu antara yang diberikan oleh Dai dengan yang diberikan oleh Yip dapat disimpulkan bahwa definisi dan karakterisasi keteramatan sistem deskriptor yang diberikan oleh Yip merupakan kejadian khusus dari definisi dan karakterisasi keteramatan sistem deskriptor kontinu yang diberikan oleh Dai. Hal ini disebabkan Yip membatasi syarat awal dari sistem hanya dapat diambil dari state-state yang terhimpun dalam himpunan I. Pembatasan tersebut mengakibatkan subsistem cepat dari sistem selalu teramati. Sehingga Yip hanya mengkarakterisasi keteramatan sistem dari subsistem lambatnya saja.

Makalah ini hanya mengulas hubungan antara definisi dan karakterisasi sistem deskriptor yang diberikan oleh Dai dan Yip. Karakterisasi lain dari keteramatan sistem deskriptor yang mudah dalam aplikasi maupun unggul dalam hal komputasi masih menjadi topik penelitian yang mungkin untuk dikembangkan.

\section{Referensi}

[1] Cristodoulou, M.A., Paraskevopoulos, P.N., Solvabiliti, 1985, Controllability, and Observability of Singular systems, Journal of Optimization Theory and Applications, vol. 45, no. 1.

[2] Dai, L., 1989, Singular Control Systems, Springer Verlag, Berlin.

[3] Grantmacher, F.R., 1974, The Theory of Matrices, Chelsea, New York.

[4] Rosenbrock, H. H., 1970, State Space MultivariableTheory, Wiley, New York.

[5] Yip. E. L., Sincovec, R. F., 1981, Solvability Controllability and Observability of Continous Descriptor Systems, IEEE Transactions on Automatic Control, vol AC-26, no 3. 